\title{
Analysis of the Possibility of the Crown Ether Structure Modification by the Introduction of Chelate Fragment
}

\author{
ALYONA IGOREVNA WOZNIAK and ANTON SERGEYEVICH YEGOROV* \\ Federal State Unitary Enterprise «State Scientific Research Institute of Chemical Reagents and High \\ Purity Chemical Substances»(FSUE "IREA"), 107076, Bogorodsky val, 3. Moscow. Russia. \\ ${ }^{*}$ Corresponding author E-mail: egorov@ irea.org.ru \\ http://dx.doi.org/10.13005/ojc/330101
}

(Received: November 16, 2016; Accepted: February 05, 2017)

\begin{abstract}
This paper describes the basic selectivity principles of polydentate ligands. There were considered choices of structure modification of crown ethers to enhancetheir complexing properties. There was compared a complexstability and the selectivity of the various metal cations of oxygencontainingcrown ethers with the nitrogen-containing crown ethers.
\end{abstract}

Keywords: Crown ether; Chelate; Structure modification; Sorbent; Complex stability; Cations.

\section{INTRODUCTION}

The polydentate reagents which are able to bind with cations that form various polyhedrons are very important in the chemistry of coordination compounds. Thereat mainly due to entropy factors there is a chelate effect. The polydentate ligand is able to form several chelate cycles, that is accompanied with an increase the equilibrium binding constant, i. e., the free energy of complex formation.

The polydentate reagents are taken an importance mainly due to two properties - the efficiency of cation binding (which is realized in the strength of the resulting complexes) and the complex formation selectivity, that applies equally to neutral ligands such as crown ethers, as well as to chelators which molecules contain both basic and acidic functionalities. The chelators are characterized with polydentate and chain flexibility bonding donor centers, and therefore the strength of the formed complexes is rather high, but relatively low selectivity.

A higher selectivity is in the cyclic polydentate ligands which include neutral crown ethers, cryptands and some other polyethers. For this reason, there are very interesting cyclopendante ligands containing cyclic nucleus to which are attached the side pendant groups bearing donor centers which is able coordinate with metal cations $^{1,2}$.

To describe the complex compound it is necessary to consider the general principles of 
complexation. This process is an equilibrium and is determined by the free energy of complexation $\mathrm{A}=\mathrm{RT}$ IgK, where $\mathrm{K}-$ is a stability constant, and the energy of complexation depends on the free energy and the entropy, but the strength of the complex is determined by the nature of the cation and the ligand.

Considering the complexing properties of the polydentate ligand, should be considered the entropy factor, because there are several binding centers in the molecule, and ligand complementarity to the coordination polyhedron of cation becomes the determining one. In the case of flexible-chain ligands with high conformational mobility, the complementarity is achieved without a lot of energy and the strength of the complex is determined by the energy of the cation binding and coordinating center. For the ligands with the rigid chainor with a small population of complex conformation the complex strength depends on the binding energy and complementarity of complexing conformation, and thus the formation of its energy and the complementarity energy becomes the determining factor for the ligands with the same set of donor centers.

On the basis of the above, logically the reagents with flexible chains of molecules can not have a high selectivity, while rigid chain ligands, other things being equal, have a high selectivity.

\section{Oxygen-containing crown ethers modified with chelating groups}

Macrocyclic polyethers modified by introducing the chelate fragment into their molecule are expand cyclopendante reagents are extensively studied in many works.

Studying the complexing ability of a compound (I) (Figure 1), which is an analog of 18-crown-6, and containing acetate groups in the structure, the authors ${ }^{3}$ established the value of logarithms of stability constants (IgK) of complexes with cations $\mathrm{NH}_{4}^{+}, \mathrm{K}^{+}, \mathrm{MeNH}_{4}^{+}$and $\mathrm{PhCH}_{2} \mathrm{CH}_{2} \mathrm{NH}_{4}{ }^{+}$in water at $25^{\circ} \mathrm{C}$, which are 3.51 , $5.48,2.88$ and 2.41 ,respectively. The values IgK complexes of 18-crown-6 with $\mathrm{NH}_{4}{ }^{+}$and $\mathrm{K}^{+}$ions are 1.10 and 2.06, respectively ${ }^{4}$. The increase of complexes compound strength (I) compared to the corresponding complexes of 18 -crown-6 is obviously related with the side acetate groups in the crown-ring of compound (I), which increases the stability of the formed complexes.

The authors of the work ${ }^{5}$ studied the complex formation of the ligand with structure (II) (Figure 1) with $\mathrm{n}=1, \mathrm{~m}=7$ and $17, \mathrm{n}=1$ and $2, \mathrm{~m}=$ 3, 7 and 13 with the ions $\mathrm{Na}^{+}, \mathrm{K}^{+}$and $\mathrm{Rb}^{+}$. It is found that the chain length $\left(\mathrm{CH}_{2}\right)_{\mathrm{m}}$ does not affect on the stability of the complexes. Conversely, increase the number of units in the macrocycle contributes to increase stability and selectivity for cations with a large ionic radius.

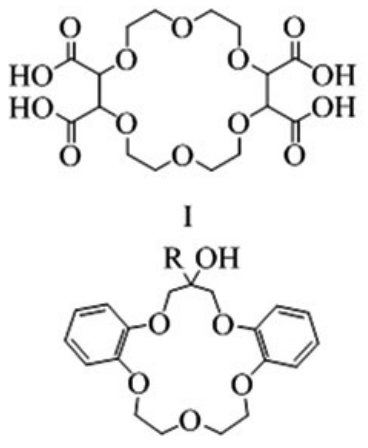

IV

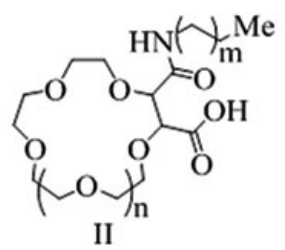<smiles>[R]C1OCCOCCOCCOC1(O)O</smiles>

$\mathrm{V}$<smiles>[R]C1(O)OCCOCCOCCOCCOCCO1</smiles><smiles>O=C(O)C1COCCO[Al]([AlH])OCO1</smiles>

$\mathrm{R}=\mathrm{H}, \mathrm{Me}, \mathrm{Ph}, n-\mathrm{C}_{10} \mathrm{H}_{21}$

1. $\mathrm{Y}=\mathrm{CH}_{2} \mathrm{CH}_{2} ; 2 . \mathrm{Y}=\left(\mathrm{CH}_{2}\right)_{3} ; 3 . \mathrm{Y}=\mathrm{CH}_{2} \mathrm{OCH}_{2} ; 4 . \mathrm{Y}=\mathrm{CH}_{2} \mathrm{OCH}_{2} \mathrm{OCH}_{2}$

Fig. 1: The structure of the oxygen-containing cyclopendante ligands 
There were derived ligands III - V6 (Figure 1), for which were defined extraction and association constants with picrates of $\mathrm{Na}^{+}$and $\mathrm{K}^{+}$. It was found that the nature of the substituent $R$ has a steric and electronic influence on the extraction process.

The compounds $\mathrm{VI}$ are effective extractants of alkali metal cations ${ }^{7}$. In the work ${ }^{7}$ for VI.3 (Figure 1) there are the stability constants with $\mathrm{Ca}^{2+}, \mathrm{Na}^{+}$and $\mathrm{K}^{+}$.

The acid VII (Figure 2), which was synthesized in the work $^{8}$ has been applied as a selective agent in relation to the uranyl ion.

For reagents VIII (Figure 2) containing a different number of oxygen donor atoms and pendent groups there were defined stability constants with the metals of the first group. It was found that with increasing of $n$ increases the equilibrium constant with the cations with larger radius $\left(\mathrm{K}^{+}\right.$and $\left.\mathrm{Cs}^{+}\right)$. At the same time the pendent groups, are apparently, donot participate in coordination with these cations, i.e. corresponding crown compounds without pendent groups have essentially the same complexing properties with respect to the alkali metal cations $^{9,10}$. For the ten ligands of structure IX.3 (Figure 2) there were studied extraction properties towards to picrates of lithium, sodium and potassium.

For the compound VIII.4 (Figure 2) there were received complexes with alkali and alkaline earth metals with composition $\mathrm{ML}, \mathrm{ML}_{2}$ and $\mathrm{M}_{2} \mathrm{~L}^{11}$. The structural research of the complex [KCNS $\left(\mathrm{L}_{2}\right)$ ] has shown that the metal ions in it are coordinated with ten donor atoms of the crown ring, while the pendant groups and CNS-counter ion are not involved in the coordination.

The compounds of the structure IX (Figure 2) were synthesized and studied in the works $^{12-15}$

The research of complexing ability of IX.2 and IX.3 ligands (Figure 2) with the ions $\mathrm{Cu}^{2+}, \mathrm{Co}^{2+}$ showed that during complexation the both pendants
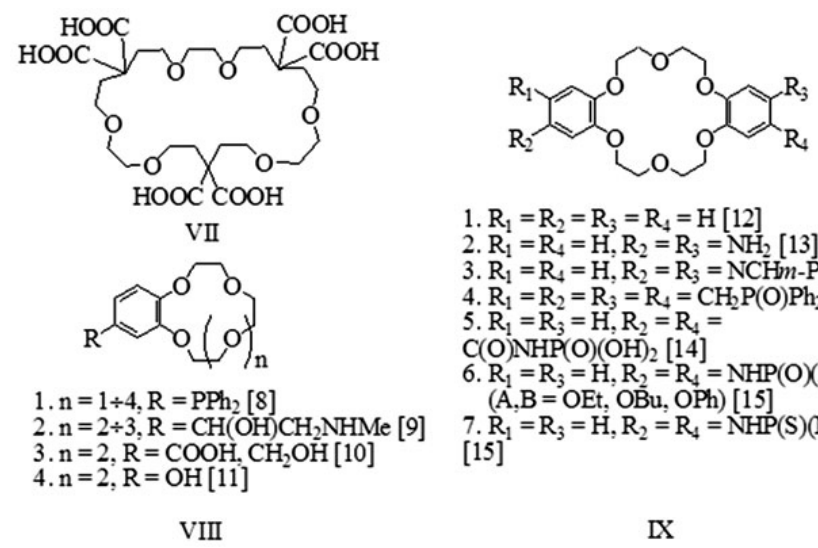

1. $R_{1}=R_{2}=R_{3}=R_{4}=H$ [12]

2. $\mathrm{R}_{1}=\mathrm{R}_{4}=\mathrm{H}, \mathrm{R}_{2}=\mathrm{R}_{3}=\mathrm{NH}_{2}[13]$

3. $\mathrm{R}_{1}=\mathrm{R}_{4}=\mathrm{H}, \mathrm{R}_{2}=\mathrm{R}_{3}=\mathrm{NCHm}-\mathrm{PhOH}$ [13]

4. $\mathrm{R}_{1}=\mathrm{R}_{2}=\mathrm{R}_{3}=\mathrm{R}_{4}=\mathrm{CH}_{2} \mathrm{P}(\mathrm{O}) \mathrm{Ph}_{2}$ [12]

5. $\mathrm{R}_{1}=\mathrm{R}_{3}=\mathrm{H}, \mathrm{R}_{2}=\mathrm{R}_{4}=$

$\mathrm{C}(\mathrm{O}) \mathrm{NHP}(\mathrm{O})(\mathrm{OH})_{2}[14]$

6. $R_{1}=R_{3}=H, R_{2}=R_{4}=N H P(O)(A B)$

(A,B = OEt, OBu, OPh) [15]

7. $\mathrm{R}_{1}=\mathrm{R}_{3}=\mathrm{H}, \mathrm{R}_{2}=\mathrm{R}_{4}=\mathrm{NHP}(\mathrm{S})(\mathrm{Me}) \mathrm{Ph}$

[15]

VIII

IX

Fig. 2 : The structure of the oxygen-containing cyclopendante ligands

Table 1: The IgK values of complexes

[ML] $]^{+}$of ligands (IX.1 and IX.4)

$\left(\mathrm{C}_{2} \mathrm{H}_{5} \mathrm{OH}: \mathrm{CHCl}_{3}-1: 1,25^{\circ} \mathrm{C}\right)^{12}$

\begin{tabular}{lllll}
\hline Cation & $\mathbf{L i}^{+}$ & $\mathbf{N a}^{+}$ & $\mathbf{K}^{+}$ & $\mathbf{C s}^{+}$ \\
\hline IX.1 & 3.48 & 3.97 & 4.51 & 3.49 \\
IX.4 & 3.09 & 3.86 & 3.95 & 3.47 \\
\hline
\end{tabular}

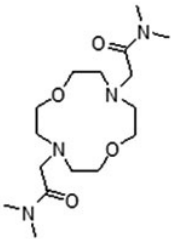

$\mathrm{X} .1$<smiles>CN(C)C(=O)CCN1CCOCCN(CCC(=O)N(C)C)CCOCC1</smiles>

$\times .2$<smiles>OCCN1CCOCCN(CCO)CCOCC1</smiles>

X.3
Fig. 3: The structure of cyclopendante ligands containing donor atoms $(\mathrm{N}, \mathrm{O})$ 
are involved and the complex has the chelate structure, that is confirmed by IR spectroscopy data.

By comparing the chelating properties of IX.4 ligands (Figure 2) with dibenzo-18-crown-6 was found that pendant groups $\mathrm{CH}_{2} \mathrm{P}(\mathrm{O}) \mathrm{Ph}_{2}$ prevent the alkaline earth metal cation coordination with the donor atoms of the macrocycle ${ }^{12}$ (Table 1).

Nitrogen-containing crown ethers modified with chelating groups

The presence of the secondary nitrogen atom in the crown ethers macrocycle offers the great opportunities for synthetic transformations of such compounds. The substitution of proton at the nitrogen atom allows to introduce chelating fragments directly into the macrocycle, and thus obtained cyclopendantes have a number of remarkable properties.

Structural investigation of X.2 ligand (Figure 3 ) which is synthesized in the work $^{16}$ showed that its donor atoms $(\mathrm{N}, \mathrm{O})$ are located at the vertices of an octahedron. The stability of<smiles>[R2]C1COCCOCCOCCN1[Z10]</smiles>

1. $\mathrm{n}=1, \mathrm{R}=\left(\mathrm{CH}_{2}\right)_{2} \mathrm{OH}$

2. $\mathrm{n}=2,3, \mathrm{R}=\mathrm{CH}_{2} \mathrm{PhOHNO}_{2}$

3. $\mathrm{n}=2, \mathrm{R}=\mathrm{CH}_{2} \mathrm{PO}_{3} \mathrm{H}_{2}$

$\mathrm{XI}$<smiles>[R]C1=NC([R])=NCCOCCOC1</smiles>

1. $\mathrm{n}=2, \mathrm{R}=\mathrm{CH}_{2} \mathrm{PO}_{3} \mathrm{H}_{2}[20]$

2. $\mathrm{n}=1, \mathrm{R}=\mathrm{CH}_{2} \mathrm{COOH} 22$

3. $\mathrm{n}=2, \mathrm{R}=\mathrm{CH}_{2} \mathrm{COOH}[21]$

4. $\mathrm{n}=2, \mathrm{R}=\mathrm{CH}_{2} \mathrm{CH}_{2} \mathrm{COOH}$

5. $\mathrm{n}=2, \mathrm{R}=\mathrm{CH}_{2} \mathrm{Py}$<smiles>O=C(O)N1CCCOCCCN(C(=O)O)CCOCCOCC1</smiles>

$\mathrm{XV}$ complexes formed by X.1-3 compounds with cations of alkaline earth elements and $\mathrm{Ag}^{+}$depends on the nature of pendants, for compound X.1 stability of the complexes with the cations listed above much higher than for X.2 and X.3.

In the work ${ }^{17}$ the complexation of XI.1 ligand (Figure 4) with the ions of alkalineearth elements was studied.

The change of selectivity of compounds XI.2 with increasing of macrocycle size with $n=2$ and $\mathrm{n}=3$ is observed ${ }^{18}$.

In the course of study of the properties of compounds XIV prepared in the work ${ }^{19}$ an ability to dissolve $\mathrm{BaSO}_{4}$ was discovered.

The compounds XIII, XIV, XV20-22 attracted the interest of a large number of researchers. Table 2 shows the values of IgK complexes [ML] with certain ligands.

The data presented in Table 2 suggests that the stability of the investigating complexes is reduced<smiles>NCCN(CCO)CCOCCCO</smiles><smiles>[R12]CCN1CCOCCOCCN(CC[R2])CCOCC1</smiles>

$\mathrm{n}=1 \div 3, \mathrm{R}=\mathrm{PO}_{3} \mathrm{H}_{2}, \mathrm{COOH}, \mathrm{NH}_{2}$ XIV<smiles>O=C(O)CN1CCOCCNCCOCCOCC1</smiles>

XVI

Fig. 4 : The structures of some cyclopendante nitrogen-containing crown ethers 
upon transition from XIII.2 to ligand XV, as well as with the increasing length of the pendant groups with the transition from XIII.3 to XIII.4. The absence of the pendant in the compound XVI leads to significant reduction in strength of the complex compared to the ligand XIII.3. In summary of the described study, it can be assumed the pendant groups participate in the coordination.

The data presented in Table 2 shows that for the cations with the radius more than $1.1 \AA$ and for the rare-earth metals the ligands XIII.3 give more stable complexes, and for all others complexes with the smaller size of the macrocycle XIII.2 are more stable. The stability constants of rare-earth metals complexes decrease monotonically from $\mathrm{Ce}$ to $\mathrm{Lu}$, correlating with decreasing radius of these cations ${ }^{23}$.

Cyclopendante ligands based on the crown polyethers are of interest as complexing agents. Thus, strontium complexes with the classical chelates typically are less stable than the analogous complexes of calcium, however the XIII.3 and $\mathrm{XV}$ compounds form complexes with the these cations which are practically identical in stability, and the ligand XIII.4 chelates the strontium more effective than calcium. The stability constant of the magnesium complex with the compound $\mathrm{XV}$ is more than by five orders lower than that of calcium. Unusually, that $\mathrm{Ni}^{2+}$ and $\mathrm{CO}^{2+}$ with the ligand $\mathrm{XIII.3,}$ XIII.4 and XV form complexes of a lower stability than alkaline earth metal ions. This may be related to the fact that the transition metal ions have a smaller ionic radius than the ions of alkaline earth metals.

\section{Azacrown ethers modified with chelating groups}

There are many cyclopendante chelating agents containing in molecule the fragment of 1,4,10-triazacyclononane and 1,4,7,10tetraazacyclododecane (cyclen) (Figure 5).

For compounds XVII.2, XVII.3, XVIII.2 and XVIII.3 the stability constants of complexes are determined for a large number of cations, therefore it is possible to compare their complexing properties (Table 3).

The selectivity of these chelators for the certain cations is explained by using the concept of complementarity of polyhedron of metal cations towards to the energetically profitable conformations of the ligand ${ }^{1,24}$. With the coordination the metal cation enters to the formed cavity, the so-called "basket", the bottom of which is the nitrogen cycle, and the walls are the pendant groups. Obviously, the selectivity will depend on the complementarity of the metal cation. The existence of a "basket" was confirmed by $\mathrm{X}$-ray diffraction of the ligand complex XVII with the ion $\mathrm{Fe}^{3+}$, its stability is very high $(\operatorname{lgK}=29.6)^{25} . \mathrm{Fe}^{3+}$ cation with the radius $\mathrm{r}=0.64 \AA$ in the $\mathrm{FeH}_{3} \mathrm{~L}$ complex is really located in the cavity of this ligand, like in the basket ${ }^{26}$.

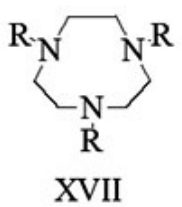

1. $\mathrm{R}=\mathrm{H}, 2 . \mathrm{CH}_{2} \mathrm{PO}_{3} \mathrm{H}_{2}, 3 \cdot \mathrm{R}=\left(\mathrm{CH}_{2}\right)_{2} \mathrm{PO}_{3} \mathrm{H}_{2}, 4=\mathrm{CH}_{2} \mathrm{COOH}, 5 .\left(\mathrm{CH}_{2}\right)_{2} \mathrm{OH}, 6 \cdot \mathrm{R}=$ $\left(\mathrm{CH}_{2}\right)_{2} \mathrm{NH}_{2}$, 7. $\mathrm{R}=\left(\mathrm{CH}_{2}\right)_{3} \mathrm{NH}_{2}, 8 . \mathrm{CH}_{2} \mathrm{CH}(\mathrm{Me}) \mathrm{OH}$ 9. $\mathrm{R}=\left(\mathrm{CH}_{2}\right)_{2} \mathrm{SO}_{3} \mathrm{H}, 10 . \mathrm{R}=\mathrm{CH}_{2} \mathrm{P}(\mathrm{O}) \mathrm{Ph}_{2}, 11 . \mathrm{R}=\mathrm{CH}_{2} \mathrm{Py}$

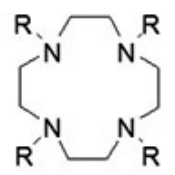

1. $\mathrm{R}=\mathrm{H}, 2 . \mathrm{CH}_{2} \mathrm{PO}_{3} \mathrm{H}_{2}$ $\mathrm{XVIII}$

Fig. 5: The structures of 1,4,7-triazacyclononane (XVII) and 1,4,7, 10-tetraazacyclododecane (XVIII) derivatives 
The chelating agent XVII.2 is selective to cations of the small ionic radius $-\mathrm{Mg}^{2+}, \mathrm{Zn}^{2+}, \mathrm{Fe}^{3+}$, with which it forms the stable complexes. With the transition to a larger radius cations the stability of the complexes is reduced by several orders ${ }^{25}$. There is a big difference in the values of the stability constants of complexes of magnesium and calcium. Usually the calcium complexes are more stable than magnesium complexes. The difference by 5 orders which is observed for XVII.2 complexes with calcium and magnesium, is unequalled (Table 3 ). The ligand also shows the highest difference of stability constants of zinc and cadmium complexes ${ }^{27}$.

The chelating agents XVIII form the stable complexes with cations with relatively large ionic radius. The ligand XVIII.2 provides a more stable complex with magnesium than with calcium (Table 3). In general, the tendency to form more stable complexes increases for the cation with an ionic radius from $0.7 \AA$ to $0.9 \AA$ (Table 3 ).

All cyclopendante phosphororganic chelating agents which have the fragment of cyclen and cyclam $(1,5,8,12$-tetraazacyclotetradecane) in the molecule, form with ion $\mathrm{Cu}^{2+}$ the particularly strong complexes with the square coordination with four nitrogen atoms of the cycle. These high

Table 2: The IgK values of complexes [ML] with ligands XIII.2-4, XV and XIV $\left(25^{\circ} \mathrm{C}, \mu=0.1, \mathrm{Me}_{4} \mathrm{NCl}, \mathrm{H}_{2} \mathrm{O}\right)$

\begin{tabular}{lccccc}
\hline Cation & XIII.2 & XIII.3 & XIII.4 & XV & XIV \\
\hline $\mathrm{K}^{+}$ & 1.7 & 3.9 & - & - & - \\
$\mathrm{Mg}^{+}$ & 7.4 & - & $<2$ & $<2$ & - \\
$\mathrm{Ca}^{2+}$ & 8.7 & 8.4 & 4 & 7.7 & - \\
$\mathrm{Sr}^{2+}$ & 7.9 & 8.3 & 4.4 & 7.7 & - \\
$\mathrm{Ba}^{2+}$ & 7.3 & 7.6 & 3.8 & 7.7 & - \\
$\mathrm{Co}^{2+}$ & 13.7 & - & - & 7 & - \\
$\mathrm{Ni}^{2+}$ & 12.2 & 7.4 & - & 7.5 & 5.4 \\
$\mathrm{Cu}^{2+}$ & 16 & 14.5 & $\sim 6-7$ & $>14$ & 10.5 \\
$\mathrm{Zn}^{2+}$ & 14.1 & 8.4 & - & 8 & 5.4 \\
$\mathrm{Cd}^{2+}$ & 13 & 11.1 & - & - & 7.8 \\
$\mathrm{~Pb}^{2+}$ & 12 & 13.6 & 8.1 & - & 10.4 \\
$\mathrm{La}^{3+}$ & 10.1 & 12.2 & - & - & 6.6 \\
$\mathrm{REE}^{2+}$ & $10.3-11.9$ & $10.8-12.2$ & - & - & $6.0-7.4$ \\
element & & & & & \\
\hline
\end{tabular}

values of stability constants of copper complexes can be attributed to the simultaneous presence of the tetraamine chelating cycle moiety and the alkylphosphonic pendent groups in these molecules as the carboxyl analogues give with $\mathrm{Cu}^{2+}$ ion the complexes with $\mathrm{lgK}$, equal to 19.0 and $18.6{ }^{28}$. The unsubstituted cyclen and cyclam form copper complexes with IgK equal to 23.3 and 26.5 , respectively ${ }^{29}$, i.e. the pendant acetate groups impede to coordination.

Apparently, the XVIII ligands have a larger size cavities, hence their ability to form high-strength complexes with such cations as $\mathrm{Cd}^{2+}, \mathrm{Hg}^{2+}, \mathrm{Pb}^{2+}$, $\mathrm{La}^{2+}$.

The authors of the work ${ }^{30}$ have synthesized the various cyclopendante ligands, which complexing ability is more dependent on the $\mathrm{pH}$ of the environment. Thus, forming a complex with zinc cations of $\mathrm{ZnL}$ composition, the rate of its formation increases from 3.1 to $48.4 \mathrm{~mol}^{-1} \mathrm{~s}^{-1}$ at $\mathrm{pH} 7.12$ and 9.00 , respectively.

1,4,7,10-Tetraazacyclododecane acetic acids are common reagents for binding cations of the transition metals and lanthanides. Thereat the complexes of such ligands in aqueous solutions

Table 3: The IgK values of complexes ML XVII.2,3 ligands and XVIII.2,3

\begin{tabular}{lllll}
\hline Cation & XVII.2 & XVII.3 & XVIII.2 & XVIII.3 \\
\hline $\mathrm{Be}^{+}$ & 11.5 & 13.4 & - & 15.9 \\
$\mathrm{Mg}^{+}$ & 11 & 6.1 & 7.3 & $<2$ \\
$\mathrm{Ca}^{2+}$ & 6.3 & $<2$ & 10.3 & $<2$ \\
$\mathrm{Sr}^{2+}$ & 5.3 & $<1$ & 9.8 & $<1$ \\
$\mathrm{Ba}^{2+}$ & 4.3 & $<1$ & 8.8 & $<1$ \\
$\mathrm{Mn}^{2+}$ & 16.6 & 12.8 & 16.9 & 12.4 \\
$\mathrm{Co}^{2+}$ & 19.7 & 13.4 & 20.8 & 14.8 \\
$\mathrm{Ni}^{2+}$ & 19.4 & 9.2 & 19 & 12 \\
$\mathrm{Cu}^{2+}$ & 21.3 & 21.3 & 25.4 & 27.1 \\
$\mathrm{Zn}^{2+}$ & 24.9 & 24.9 & 24.8 & 24.6 \\
$\mathrm{Cd}^{2+}$ & 19.7 & 19.7 & 22.9 & 20.8 \\
$\mathrm{Hg}^{2+}$ & 23 & 23 & 25.1 & 29.6 \\
$\mathrm{~Pb}^{2+}$ & 22.1 & 22.1 & 23.3 & 16.3 \\
$\mathrm{Fe}^{3+}$ & 29.6 & 29.6 & - & - \\
$\mathrm{La}^{3+}$ & 14.3 & 14.3 & - & - \\
\hline
\end{tabular}


have a high thermodynamic and kinetic stability. For example, ${ }^{64} \mathrm{Cu}$ isotope complexes with $1,4,7,10$ tetraazacyclododecane-1,4,7,10-tetraacetic acid (DOTA) due to their high stability are used as conjugants in biochemistry ${ }^{31}$. The abnormally high stability of the DOTA complexes with $\mathrm{Gd}^{2+}$ cation allows to use this compound as a contrast agent for magnetic resonance imaging ${ }^{32,33}$.

The upcoming trend in the modern chemistry of the cyclopendante compounds is the creation of ligands containing the reactive moiety in the molecule where by a molecule can be immobilized on the matrix of polymers or peptides ${ }^{32}$.

In summary, the described research results show that the derivatives of crown ether, nitrogencontaining crown ethers, azacrown containing chelating groups and cyclopendante compounds are the most effective complexing agents. By varying their chemical structure, the size of the crown ring, the nature of donor atoms of the ring and pendent groups it is possible to attain the high selectivity towards almost any metal cation.

Thus, the use of these compounds for the creation of effective and selective sorption materials is a considerable interest.

Determination of the commercial importance of the developed functional sorbents modified with the chelating fragments in solving practical problems

The application of sorption materials is associated with the pollution of industrial waste water with metal cations, including their radioactive isotopes. By varying the nature of complexing groups in the sorbent it is possible to attend the selectivity and increase binding effectiveness towards to one or another metal cation. Thus, it is possible to create sorption materials with desired properties to solve the specific industrial problems.
The commercial potential of these materials is high. This is due to their sorption capacity, the complexing ability, the equipment processability used for the absorption of metals from industrial waste water, the possibility of repeated use and simplicity of utilization of used material.

The complexing sorbents are of great interest for the nuclear industry. There is a number of problems associated with the extraction and separation of the radioactive isotopes. Sorbents containing crown ether fragments can be used for selective binding of cations of cesium radioactive isotopes and other alkali metals and their subsequent separation.

\section{CONCLUSION}

The introduction of chelating groups into sorbents allows to solve the problems associated with the recovery of radioactive isotopes of transition metals, particularly - cobalt isotopes.

Finally, the use of sorption materials containing a crown ether and chelating fragments at the same time, can allow to solve the problems associated with the separation of radio isotope all-up, i.e. strip from contaminated waters the isotopes of alkali and transition metals, that is not possible for monofunctional sorbents.

\section{ACKNOWLEDGEMENTS}

Applied researches are carried out with state financial support represented by the Ministry of Education of Russia under the Agreement on granting subsidies N14.625.21.0034 of October 27, 2015. (Unique identifier of Applied Scientific Researches (project) RFMEFI62515X0034).

\section{REFERENCES}

1. Kabachnik, M.I. Mendeleev ChemistryJournal. 1984,29 (3), 272-282.

2. Schultz, R.A.;Dishong, D.M.;Gokel, G.W. J. Amer. Chem. Soc.1982, 104(2), 625-626.

3. Behr, J.P.; Lehn, J.M.;Viering, P. J. Chem. Soc.
Chem. Commun.1976, 621-623.

4. Yacimirskij, K.B.;Kriss, E.E.;Gvyazdovskaya, V.L.The stability constants of metal complexes with bioligands. Kyiv: Nauk, dumka, 1979, 284. 
5. $\quad$ Frederick, L.A.;Fyles, T.M.; Gurprasad, N.P.; Whitfield, D.M. Canad. J. Chem.1981,59(12), 1724-1733.

6. Pugia, M.J.; Knudsen, B.E.C.; Cason, V.;Bartsch, R.A.J. Org. Chem.1987, 52 (4), 541-547

7. Strzelbicki, J.;Bartsch, R.A. Anal. Chem.1981,53(14), 2251-2253.

8. Tabushi, I.;Kabuke, Y. J. Amer. Chem. Soc.1980,102(4), 5947-5948.

9. Okano, T.;Iwahara, M.;Konishi, H.;Kiji, J. J. Organomet.Chem. 1988,346(2), 267-275.

10. Fenton, D.E.;Parkin, D.; Newton, R.F. J. Chem. Soc. Perkin Trans.Part I. 1981.449-454.

11. Weber, E.;Crugler, M. Irong.chim. acta. 1982. 61(1), 33-38.

12. Yacimirskij, K.B.;Kabachnik, M.I.; Cymbal, L.V. Zh. Neorg.Khim.1985,30, 976-981.

13. Yacimirskij, K.B.;Sinyavskaya, E.I.; Cymbal, L.V. Zh. Neorg.Khim.1983,28, 946-952.

14. Lukoyanov, N.V.;Van'kin, G.I.;Juravleva, L.V.;Panarin, V.A.;Rajewski, O.A. Biological membranes (Rus).1985,2 (1), 71-76.

15. Kudrya, T.N.;Tochilkina.L.M.;Kazachenk, V.P.;Rajewski, O.A.;Pinchuk, A.M.Russ. J. Gen. Chem.1985,55 (9), 2021-2024.

16. Matthes, K.E.; Parker, D.;Bushmann, H.J.; Ferguson, H. Tetrahedron Lett.1987,28(45), 5573-5576.

17. Calverley, M.J.; Dale, J. ActaChem. Scand. 1982,36B, 241-247.

18. Nakamura, H.;Sakka, H.; Takagi, M.; Ueno, K.Chem. Lett.1981, 10(9), 1305-1306.

19. Jong, F.;Zon, A.;Reinhoudt, D.N.;Torny, G.J.;Tomassen, H.P.M. Recüeil.1983, 102(3), 164-173.

20. Richardson, N.M.; Sutherland, I.O.;Camilleri, P.; Page, J.A. Tetrahedron Lett.1985,26(31),
3739-3742.

21. Yamashita, T.; Nakamura, H.; Takagi, M.; Ueno, K. Bull. Chem. Soc. Jap. 1980,53(6), 1550-1554.

22. Thom, V. J.;Shaikjee, M.S.; Hancock R.D. Inorg.Chem. 1986,25(17),2992-3000.

23. Chang, C.A.; Rowland, M.E. Inorg.Chem. 1983,22(26), 3866-3869.

24. Medved',T.Ya.;Kabachnik, M.I.;Goryunova, I.B.;Shcherbakov, B.K.;Bel'skii, F.I.;Petrovskii, P.V.;Polikarpov, Yu.M.Russ. Chem. Bull.1988,37(9),1890-1895.

25. Kabachnik, M.I.;Medved, T.Ya.;Polikarpov, Yu.M. Rus. Chem. Bull. 1982, 1669-1670.

26. Antipin, M.Yu.; Baranov, A.P.;Kabachnik, M.I. Proceedings of the USSR Academy of Science.1986,287, 130-133.

27. Martell, A.K.; Smith, R.M. Critical stability constants. N.Y.; L.: Plenum press. 1982.15:1131.

28. Stetter, H.; Frank, W.;Mertens, R. Tetrahedron. 1981,37(4), 767-772.

29. Thöm, V.J.;Hosken, G.D.; Hancock, R.D. Inorg. Chem. 1985,24(21),3378-3381.

30. Subat, M.;Woinaroschy, K.;Gerstl, C.;Sarkar, B.;Kaim, W.;Konig, B. Inorg.Chem. 2008,47(11),4661-4668.

31. Ait-Mohand, S.;Fournier, P.;DumulonPerreault, V.; Kiefer, G.E.;Jurek, J.; Ferreira, C.L.;Bénard, F.;Guérin, B. Bioconjugate Chem. 2011,22(8),1729-1735.

32. Jagadish, B.; Guntle, G.P.;Zhao, D.;Gokhale, V.;Ozumerzifon, T.J.;Ahad, A.M.; Mash, E.A.;Raghunand, N.J. Med. Chem.2012,55(23),10378-10386.

33. Marom, H.; Miller, K.;Bechor-Bar, Y.;Tsarfaty, G.;Satchi-Fainaro, R.;Gozin, M. J. Med. Chem. 2010,53(17),6316-6325. 